Article

\title{
Experiment and Computation of Morphological Response to a Vegetation Patch in Open-Channel Flows with Erodible Banks
}

\author{
Hyung Suk Kim ${ }^{1, * \mathbb{C}}$, Ichiro Kimura ${ }^{2} \mathbb{D}$ and Yasuyuki Shimizu ${ }^{3}$ \\ 1 Department of Land, Water and Environment Research, Korea Institute of Civil Engineering and Building \\ Technology, Goyang 10223, Korea \\ 2 Graduate School of Science and Engineering for Research, University of Toyama, Toyama 930-8555, Japan; \\ ichiro@sus.u-toyama.ac.jp \\ 3 Graduate School of Engineering, Hokkaido University, Sapporo 060-0808, Japan; yasu@eng.hokudai.ac.jp \\ * Correspondence: hskim0824@kict.re.kr
}

Received: 23 September 2019; Accepted: 23 October 2019; Published: 28 October 2019

\begin{abstract}
This study describes morphological changes with a vegetation patch using both laboratory experiments and numerical simulations. Four experimental cases are carried out with two patch densities and without a patch. The patch is constructed with emergent cylinders of $5 \mathrm{~mm}$ in a staggered array and it is located at the mid-channel. A 2D depth-averaged model is proposed to simulate flow and morphological change with vegetation. For non-vegetation cases, channel widening occurs with bank erosion, whereas the added patch in open channels causes significant bank erosion opposite and downstream of the patch, and failed sediment is deposited downstream of the patch. Local scour is observed near the lateral edge of the patch, and its depth increases with increasing patch density. Small-scale scour occurs in the immediate vicinity of cylinders within the patch due to increased turbulence. Averaged channel width increases with increasing discharge, channel slope and the patch density. Comparisons with experimental data show the numerical model predicts spatial patterns of erosion and deposition as well as lateral bank erosion caused by the vegetation patch reasonably well, so could be a useful tool for the future design and assessment of river restoration works involving vegetation.
\end{abstract}

Keywords: bank erosion; vegetation patch; numerical model; experiment; morphological change

\section{Introduction}

In the last few decades, global warming has become a serious problem in the world. In many countries located in mid-latitude zone, it brought the regional torrential rain events, which has increased destructive floods. From the late 19th century, many channels have been denudated and straightened for improving discharge capacity when heavy rain occurs, but they have caused unexpected results such as the destruction of ecosystems and water pollution. Also, a lot of dams have been constructed to regulate discharge upstream of rivers, but those have affected channel morphology downstream of dams. Riverbed degradation has been caused downstream of the dam and sediment transport has been cut by the dam and, therefore, creates new environment, which give vegetation more chances to grow and expand on the sandbars. Vegetation established on sandbars inhibits sediment movement and it accelerates the stability of the riverbed. Recently, attempts to restore ecology and landscape of rivers have increased to meet the desire of people for eco-friendly rivers. Vegetation has been used as an ingredient for river restoration to improve water quality and in-stream habitat. In contrast, vegetation in the streams is sometimes considered undesirable because it significantly increases water levels in the flood stage. In fact, removing vegetation is one of the methods to reduce flood risk but it may 
exacerbate the ecology as mentioned above. Therefore, an issue is how to balance the ecology and flood control [1].

The presence of vegetation in the watercourse dramatically alters flow directions, flow velocities, turbulence intensities and Reynolds stresses laterally and vertically [2] and therefore, they induce significant sediment transport and morphological change [3-7]. Furthermore, vegetation reduces the local velocity so it causes a reduction of erosion and promotes deposition in the stream and floodplain.

In particular, many researches have focused on flow velocities and structures influenced by additional drag force in partly vegetated channels. White and Nepf [8] observed the flow structure and momentum exchange at the interface between vegetation zone and non-vegetation zone in a partly vegetated open channel and coherent vortices were generated at the interface between them. Secondary current was generated by partial vegetation zone, and the magnitude of the secondary currents increased with increasing vegetation densities [9].

Vegetation in the stream not only can alter channel morphology but also cause deposition and erosion around and within the vegetation zone $[10,11]$. Tal and Paola [6] showed the channel planform could be changed from a braided to single thread by vegetation. Jang and Shimizu [5] carried out laboratory experiments to investigate the effects of vegetation on morphology with various vegetation densities. They observed the flow direction was affected by vegetation, and vegetation stabilized banks. Alternating vegetation in the open channel for restoring a straight and degraded stream not only affected channel shapes but also caused bar and pool developments [7]. Rominger et al. [11] conducted outdoor, field-scale experiments to examine influences on vegetation on sandbars in meandering channel and they found added vegetation on sandbars caused erosion near the edges of vegetation zone and formed the new sandbar area due to the spatial acceleration. Zong and Nepf [12] investigated deposition patterns in a patch of vegetation located at a side wall of an open channel. Net deposition increased from the leading edge of the patch in stream-wise direction, and it decreased beyond the diverging region. The deposition pattern was almost uniform within the patch in a transverse direction.

A number of numerical models have been proposed to simulate flow and sediment transport through vegetation. Darby [13] developed the hydraulic model to predict stage-discharge curves in non-uniform channel cross sections with flexible or rigid vegetation. Tominaga et al. [14] simulated mean flow structures and momentum transport processes in curved open channels with vegetation using a two-dimensional numerical model including the dispersion term of the secondary current. Tsujimoto [3] performed numerical analysis of morphological changes around a vegetated island using a two dimensional depth averaged model with $k-\varepsilon$ turbulence closure. Wu et al. [15] presented a sophisticated numerical model by introducing vegetation density into governing equations, and the model was tested compared to existing experimental data. Li and Millar [16] carried out long-term simulations using a 2-D numerical model, and they investigated the effects of vegetated banks and floodplains on meandering and braiding developments.

While many studies have discussed the influence of vegetation on flow, sediment transport and morphological change, there are few studies on the effect of vegetation patch on erosion and deposition in open channel flows in erodible banks. The objective of this study is to improve understanding of spatial patterns of erosion and deposition as well as morphological behaviors that are affected by a vegetation patch in an open channel with erodible bank using both experiments and computations. Laboratory experiments are conducted to investigate morphological changes near the rigid-emergent patch of vegetation, which is modeled by circular cylinders. Four experimental cases are tested with two patch densities and without a patch. A 2D depth-averaged model that is capable of simulating flow and morphological change with a vegetation patch in an open channel flow is proposed considering an erodible bank. The model is applied to partly-vegetated open channel flows, and the simulated results are compared to measured data available in the literature for a validation of the model. The features of morphological change near the patch are investigated, and the impact of the patch density on erosion and deposition within and around the patch is discussed. 


\section{Laboratory Experiment}

Experiments were conducted in a flume $8.0 \mathrm{~m}$ long and $0.6 \mathrm{~m}$ wide with wooden sidewall (Figure 1a). The flume was filled with well-sorted sand with $0.9 \mathrm{~mm}$ mean diameter and the initial channel was set with a bottom width $w_{\mathrm{b}}$ of $0.2 \mathrm{~m}$, a height $h_{0}$ of $0.05 \mathrm{~m}$ and $45^{\circ}$ bank slope (Figure $1 \mathrm{~b}$ ). The diameter of the sand was determined so as to make the Shields number becomes within the same range as real rivers and to enable clear observation of local scours around the vegetation patch. A model patch of vegetation which was idealized as emergent and staggered array of circular cylinders of diameter $5 \mathrm{~mm}$ was placed at the center of the channel (i.e., at $4.0 \mathrm{~m}$ from the upstream end) and extended into the center of the channel in the transverse direction (Figure 1a,b). It is difficult to determine the diameter of the cylinder reasonably considering both the scales of the vegetation patch and the sand particle diameter. We determined it as $5 \mathrm{~mm}$ by trial and error through some preliminary experiments with different diameters. Two patch densities $\left(\varphi=3.12\right.$ and $\left.5.44 \mathrm{~m}^{-1}\right)$, which were defined to a frontal area per unit volume, were tested and the shape of the patches was a rectangular $0.5 \mathrm{~m}$ long and $0.25 \mathrm{~m}$ wide. The scale of the patch was determined by considering many small or medium-sized rivers with vegetation in Korea and Japan. It is necessary to examine the effects of patch scales on the bed morphology in the next step. Figure 1 showed a definition of the patch where $S_{x}$ and $S_{y}$ were spacing of cylinders, which were $3.0 \mathrm{~cm}\left(\varphi=5.44 \mathrm{~m}^{-1}\right)$, and $4.0 \mathrm{~cm}\left(\varphi=3.12 \mathrm{~m}^{-1}\right)$.

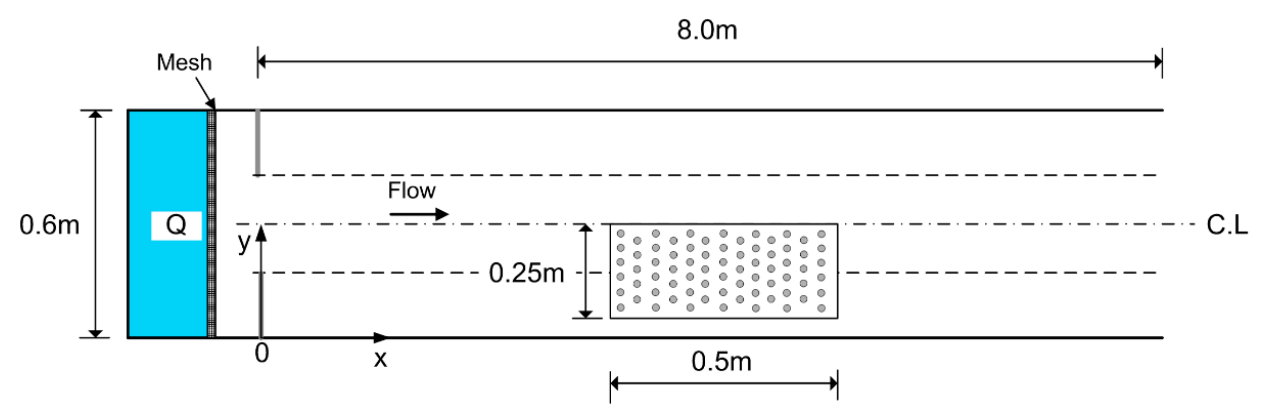

(a) Top view

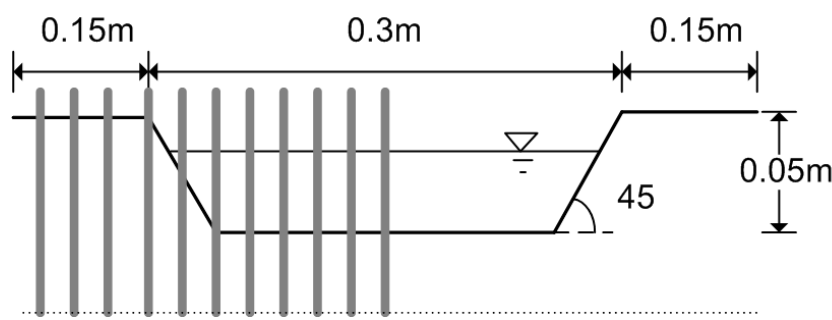

(b) Initial channel with a vegetation patch in a cross section

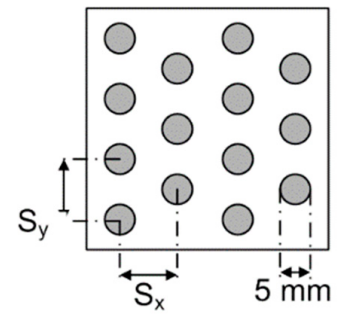

(c) Cylinder arrangement

Figure 1. Schematic diagram of the experimental flume.

The experimental parameters for the patch of vegetation are summarized in Table 1.

Table 1. Experimental parameters for vegetation patch.

\begin{tabular}{ccc}
\hline Vegetation Condition & Low Density (LD) & High Density (HD) \\
\hline Spacing $\left(\mathrm{S}_{\mathrm{x}}=\mathrm{S}_{\mathrm{y}} \mathrm{m}\right)$ & 0.04 & 0.03 \\
Number of cylinders & 78 & 136 \\
Density $\left(\mathrm{m}^{-1}\right)$ & 3.12 & 5.44 \\
\hline
\end{tabular}

Four experimental cases were performed with two patch densities and without the patch under subcritical flow conditions ( $\mathrm{Fr}=0.75 \sim 0.85$ ). Three different discharges and two different channel slopes were used for the experiments. Before the start of experiments, the water discharge and the channel slope were set, and small discharge was run into the channel to saturate the bed. Sediment 
was supplied at the upstream end of the channel to keep the bed shape without local disturbance. The width was measured at some locations every $30 \mathrm{~min}$, using point gages. The bed surface was surveyed every $10 \mathrm{~cm}$ in the longitudinal direction from 1.0 to $7.0 \mathrm{~m}$, and every $0.4 \mathrm{~cm}$ in the transverse direction, respectively but measured every $2 \mathrm{~cm}$ in the longitudinal direction near the patch, from $3.25 \mathrm{~m}$ to $4.75 \mathrm{~m}$, using a laser bed profiler at the end of each experimental case after draining out of the channel, and carefully removing the patch. After experiments, an initial channel shape was reformed. The experiment duration was maintained at $2 \mathrm{~h}$ for all experiments. The experimental conditions are summarized in Table 2.

Table 2. Experimental conditions.

\begin{tabular}{ccccc}
\hline Hydraulic Condition & Case $\mathbf{1}$ & Case $\mathbf{2}$ & Case 3 & Case 4 \\
\hline Discharge $(\mathrm{L} / \mathrm{s})$ & 1.33 & 1.79 & 2.16 & 1.33 \\
Initial bed slope & $1 / 250$ & $1 / 250$ & $1 / 250$ & $1 / 180$ \\
Mean diameter $(\mathrm{mm})$ & 0.9 & 0.9 & 0.9 & 0.9 \\
\hline
\end{tabular}

\section{Numerical Model}

\subsection{Governing Equations}

A depth-averaged, two-dimensional numerical model was proposed to simulate flow, sediment transport and progress of bed morphology in an open channel with vegetation. Governing equations of this model are based on depth-averaged continuity equation and momentum equations described as:

$$
\begin{gathered}
\frac{\partial(1-c) h}{\partial t}+\frac{\partial(1-c) M}{\partial x}+\frac{\partial(1-c) N}{\partial y}=0 \\
\frac{\partial(1-c) M}{\partial t}+\frac{\partial(1-c) u M}{\partial x}+\frac{\partial(1-c) v M}{\partial y}=-g h(1-c) \frac{\partial H}{\partial x}-(1-c) \frac{\tau_{b x}}{\rho} \\
+\frac{\partial\left[(1-c)\left(-\overline{u^{\prime 2}} h\right)\right]}{\partial x}+\frac{\partial\left[(1-c)\left(-\overline{u^{\prime} v^{\prime}} h\right)\right]}{\partial y}+v\left[\frac{\partial}{\partial x}\left(h \frac{\partial(1-c) u}{\partial x}\right)+\frac{\partial}{\partial y}\left(h \frac{\partial(1-c) u}{\partial y}\right)\right]-F_{x} \\
\frac{\partial(1-c) N}{\partial t}+\frac{\partial(1-c) u N}{\partial x}+\frac{\partial(1-c) v N}{\partial y}=-g h(1-c) \frac{\partial H}{\partial y}-(1-c) \frac{\tau_{b y}}{\rho} \\
+\frac{\partial\left[(1-c)\left(-\overline{u^{\prime} v^{\prime}} h\right)\right]}{\partial x}+\frac{\partial\left[(1-c)\left(-v^{\prime 2} h\right)\right]}{\partial y}+v\left[\frac{\partial}{\partial x}\left(h \frac{\partial(1-c) v}{\partial x}\right)+\frac{\partial}{\partial y}\left(h \frac{\partial(1-c) v}{\partial y}\right)\right]-F_{y}
\end{gathered}
$$

where $h=$ water depth; $u, v=$ depth-averaged velocity; $M, N=$ discharge flux $(M=h u, N=v h)$; $c=$ concentration of vegetation; $g=$ gravitational acceleration; $\rho=$ density of water; $\tau_{b x}, \tau_{b y}=$ bottom shear stress; $H=$ water surface elevation $\left(h+z_{b}\right) ;-\overline{u^{\prime}},-\overline{v^{\prime}},-\overline{u^{\prime} v^{\prime}}=$ depth-averaged Reynolds stress tensors; $v=$ kinetic viscosity.

Components of the bottom shear-stress vector are evaluated by:

$$
\tau_{b x}=f \rho u \sqrt{u^{2}+v^{2}}, \tau_{b y}=f \rho v \sqrt{u^{2}+v^{2}}
$$

where $f=$ friction coefficient, which is calculated using Manning's roughness coefficient as $g n^{2} / R_{\mathrm{s}}{ }^{1 / 3}$. $R_{\mathrm{S}}$ is spacing hydraulic radius which defined as $R_{S}=b_{v} h /\left(2 h+b_{v}\right) ; b_{v}$ is the spacing of stems [17]. When vegetation density become very low or there is no vegetation, $R_{s}=h$.

Components of the drag force due to vegetation calculated by:

With

$$
\begin{aligned}
& F_{x}=\frac{1}{2} C_{D} \varphi h u_{v} \sqrt{u^{2}+v^{2}}=C_{D} \frac{2 c}{\pi D} h u_{v} \sqrt{u^{2}+v^{2}} \\
& F_{y}=\frac{1}{2} C_{D} \varphi h v_{v} \sqrt{u^{2}+v^{2}}=C_{D} \frac{2 c}{\pi D} h v_{v} \sqrt{u^{2}+v^{2}}
\end{aligned}
$$

$$
\varphi=\frac{N_{v} D \min \left(h, h_{v}\right)}{L_{v} W_{v} h}, \quad c=N_{v} \frac{\pi D^{2}}{4} \frac{\min \left(h, h_{v}\right)}{L_{v} W_{v} h}
$$


where $C_{D}=$ drag coefficient; $\varphi=$ vegetation density; $N_{\mathrm{v}}=$ the number of stems; $D=$ diameter of a stem; $L_{v}=$ length of vegetated area; $W_{v}=$ width of vegetated area; $h_{v}=$ vegetation height. In Equation (5), $u_{v}$ and $v_{v}$ are the flow velocity acting on vegetation which should be equal to depth-averaged velocity, $u$ and $v$, respectively for emergent conditions [15].

In an isolated cylinder, drag coefficient, $C_{D}$ is based on upstream velocity of a cylinder, $u_{v}$ shown in Figure 2, so that in a cylinder array, the drag coefficient is significantly affected by the population density of cylinders, influencing upstream velocity of cylinders. For instance, Tanino and Nepf [18] presented $C_{D}$ increased with vegetation density and $C_{D}$ decreased with cylinder Reynolds number. Stone and Shen [19] proposed the flow velocity, $u_{v m}$ between cylinders shown in Figure 2 had very little variation for a wide range of density and cylinder Reynolds number in comparison with $u_{v}$ and an averaged value, $C_{D M}$ of 1.05 based on $u_{v m}$ was a reasonable estimation for $C_{D}$. The relation between $C_{D M}$ and $C_{D}$ is:

$$
C_{D}=C_{D M} \frac{u_{v m}^{2}}{u_{v}^{2}}
$$

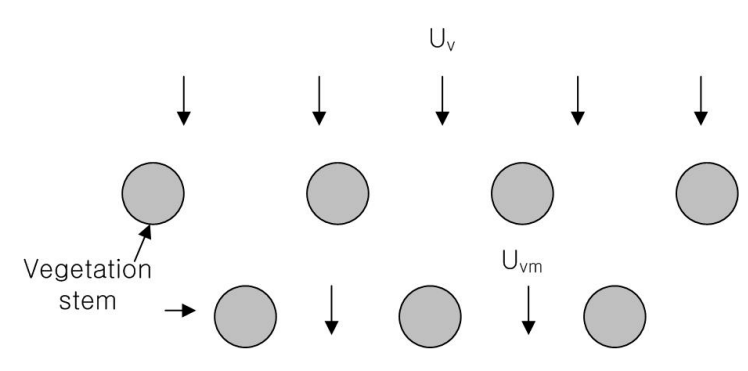

Figure 2. Definition of $u_{\mathrm{v}}$ and $u_{\mathrm{vm}}$ in vegetation region.

If the vegetation stems are arrayed on staggered arrangement, $u_{v}$ becomes $u_{v m}\left(1-D \sqrt{N_{v}}\right)$. Therefore, Equation (6) can be derived in unit volume as:

$$
C_{D}=C_{D M} /\left(1-\sqrt{\frac{4 c h}{\pi \min \left(h, h_{v}\right)}}\right)^{2}
$$

Constitutive equations of Reynolds Stress are expressed by:

$$
-\overline{u_{i}^{\prime} u_{j}^{\prime}}=v_{t}\left(\frac{\partial u_{i}}{\partial u_{j}}+\frac{\partial u_{j}}{\partial u_{i}}\right)-\frac{2}{3} k \delta_{i j,} \quad i, j=1,2
$$

where $v_{t}$ is the eddy viscosity. To determine the value of the eddy viscosity, both 0 -equation and $k-\varepsilon$ turbulence models are adopted and the simulated results were compared.

1. 0-equation

$$
v_{t}=\alpha h u_{*}
$$

where $\alpha=$ constant value between 0.1 and 1.0 [20]. In this study, 0.2 was used. Nezu and Nakagawa [21] proposed an empirical formula for vertical distribution of $k$ as:

$$
\frac{k}{u_{*}}=4.78 \exp \left(-2 \frac{z}{h}\right)
$$

where $k=$ turbulent kinematic energy; $z=$ distance from the bottom; $u_{*}=$ local friction velocity. The turbulent kinetic energy integrated in a vertical direction become the following formula:

$$
k=\gamma_{k} u_{*}^{2}, \quad \gamma_{k}=2.07
$$


2. $k-\varepsilon$ model

$$
v_{t}=c_{\mu} \frac{k^{2}}{\varepsilon}
$$

where $c_{\mu}$ is an empirical constant $(=0.09), k$ is the turbulent kinetic energy and $\varepsilon$ is the turbulence dissipation rate which are determined by the following transport equations:

$$
\begin{gathered}
\frac{\partial k}{\partial t}+u \frac{\partial k}{\partial x}+v \frac{\partial k}{\partial y}=\frac{\partial}{\partial x}\left(\frac{v_{t}}{\sigma_{k}} \frac{\partial k}{\partial x}\right)+\frac{\partial}{\partial y}\left(\frac{v_{t}}{\sigma_{k}} \frac{\partial k}{\partial y}\right)+\left(P_{h}+P_{k b}+P_{v}-\varepsilon\right) \\
\frac{\partial \varepsilon}{\partial t}+u \frac{\partial \varepsilon}{\partial x}+v \frac{\partial \varepsilon}{\partial y}=\frac{\partial}{\partial x}\left(\frac{v_{t}}{\sigma_{k}} \frac{\partial \varepsilon}{\partial x}\right)+\frac{\partial}{\partial y}\left(\frac{v_{t}}{\sigma_{k}} \frac{\partial \varepsilon}{\partial y}\right)+c_{\varepsilon 1} \frac{\varepsilon}{k}\left(P_{h}+c_{\varepsilon 3} P_{v}\right)+P_{\varepsilon b}-c_{\varepsilon 2} \frac{\varepsilon^{2}}{k}
\end{gathered}
$$

with,

$$
\begin{gathered}
P_{h}=v_{t}\left[\left(2\left(\frac{\partial u}{\partial x}\right)^{2}+\left(\frac{\partial u}{\partial y}+\frac{\partial v}{\partial x}\right)^{2}+2\left(\frac{\partial v}{\partial y}\right)^{2}\right)\right] \\
P_{\varepsilon b}=c_{\varepsilon \beta} c_{\varepsilon} c_{\mu}^{-1 / 2} c_{f}^{-3 / 4} u_{*}^{4} / h^{2} \\
P_{v}=c_{v k}\left(F_{x} u_{v}+F_{y} v_{v}\right) / \rho(1-c)
\end{gathered}
$$

where, $c_{v k}, c_{\varepsilon 1}, c_{\varepsilon 2}, c_{\varepsilon 3}, c_{\varepsilon \beta}, \sigma_{k}$, and $\sigma_{\varepsilon}$ are empirical constants. In the present computations, we use the following standard values by Launder and Spalding [22]: $\sigma_{\varepsilon}=1.3, \sigma_{k}=1.0, c_{\varepsilon 1}=1.44, c_{\varepsilon 2}=1.92$ and Lopez and Garcia [23]: $c_{\varepsilon 3}=1.33, c_{v k}=1.0$. Also, $c_{\varepsilon \beta}$ uses 3.6 [24,25].

The bed elevation change by implicating erosion and deposition of sediment is calculated by two-dimensional sediment continuity equation:

$$
\frac{\partial(1-c) z_{b}}{\partial t}+\frac{1}{(1-\lambda)}\left(\frac{\partial(1-c) q_{b}^{x}}{\partial x}+\frac{\partial(1-c) q_{b}^{y}}{\partial y}\right)=0
$$

where $z_{b}=$ bed elevation; $\lambda=$ porosity of the bed material; $q_{b}^{x}, q_{b}^{y}=$ bedload transport rate per unit width in $x$ and $y$ directions, respectively, which are given by defining streamline direction, $s$ and transverse direction, $n$ :

$$
\begin{aligned}
& q_{b}^{x}=q_{b}^{s} \cos \theta-q_{b}^{n} \sin \theta \\
& q_{b}^{y}=q_{b}^{s} \sin \theta-q_{b}^{n} \cos \theta
\end{aligned}
$$

The sediment transport rate along the streamline direction is calculated using the formula, included the effect of bank slope and gravity on side bank proposed by Kovacs and Parker [26] based on formula of the Ashida and Michiue [27]. Modified by Yamaguchi and Izumi [28] as:

$$
q_{b}^{s}=\frac{a^{1 / 2}}{\mu_{c}}\left[\tau_{*}-\tau_{* c}\left(1+\frac{1}{\mu_{c}} \frac{\partial z_{b}}{\partial s}\right)\right]\left[\tau_{*}^{1 / 2}-\tau_{* c}^{1 / 2}\left(1+\frac{1}{2 \mu_{c}} \frac{\partial z_{b}}{\partial s}\right)\right]\left(1-\frac{1}{\mu_{c}} \frac{\partial z_{b}}{\partial s}\right) \sqrt{s g d^{3}}
$$

where $a=u_{*} / V, \tau_{*}=$ non-dimensional shear stress; $\tau_{*_{\mathrm{C}}}=$ non-dimensional critical shear stress; $\mu_{\mathrm{c}}=$ the dynamic Coulomb friction factor $(=\tan \phi$, where $\phi=$ angle of repose $) ; d=$ grain size and $s=$ specific weight of sediment in fluid.

The sediment transport rate in the $n$ direction $q_{b}^{n}$, is calculated by using the Hasegawa equation [29] as:

$$
q_{b}^{n}=q_{b}^{s}\left(\frac{u_{b n}}{u_{b s}}-\sqrt{\frac{\tau_{* c}}{\mu_{s} \mu_{k \tau_{*}}}} \frac{\partial z_{b}}{\partial n}\right)
$$

where $u_{b n}, u_{b s}=$ near-bed velocities in the $s$ and $n$ directions; $\mu_{s}=$ static friction factor $(=0.7)$ and $\mu_{k}=$ kinetic friction factor $(=0.5)$. 
The near-bed velocities in the $s$ - and $n$ - directions is evaluated by:

$$
\begin{gathered}
u_{b s}=\beta V \\
u_{b n}=N_{*} \frac{h}{r_{s}} u_{b s}
\end{gathered}
$$

where $\beta=3(1-\sigma)(3-\sigma)$ in which $\beta$ was assumed to be parabolic distribution of flow in the vertical direction [30]. $\Sigma=3 /(\chi \kappa+1) ; \chi=$ velocity factor $\left(=V / u^{*}\right) ; \kappa=$ von Karman constant $(=0.4) ; r_{\mathrm{s}}=$ radius of curvature of the streamline; $N^{*}=$ coefficient for secondary flow, which varied from 7.9 to 11.4 [31]. In this study, it is assumed to be 10.0.

In order to calculate channel widening with bank erosion, the bank-erosion model proposed by Hasegawa [32] is adopted in the present model. It is calculated under the assumption that as the gradient of the bank, which is calculated using the bed elevation of neighboring grids becoming greater than the angle of repose, bank corruption takes place until the slope becomes just same as the angle of repose. The failed sediment is included in the process of computation and the total sediment mass in the computational domain is conserved. In the present study, we test the sensitivity to angle of repose, and then the angle of repose is assumed to be 30 degrees.

\subsection{Numerical Scheme and Boundary Conditions}

The governing equations, i.e., continuity and momentum equations for flow are solved with the finite-volume method (FVM) on a full staggered grid. The Quadratic Interpolation for Convective Kinetics (QUICK) scheme, which has second order accuracy in space, is employed for the convection terms and central differencing is applied to the diffusion terms in momentum equations. The upwind scheme is used for continuity equation for sediment transport. The second order Adams-Bashforth scheme is used for time integration in each equation.

Computational domain is $8.0 \mathrm{~m}$ long and $0.6 \mathrm{~m}$ wide. The Computational grids are used with 400 in the streamwise direction and 60 in the transverse direction. The computational time step is $0.001 \mathrm{~s}$ and each simulation was lasted for $2 \mathrm{~h}$. A specified discharge at upstream end and zero gradient condition at downstream end are given. A no-slip condition is used at both sidewalls and emerged banks. For the boundary of bedload flux, the zero gradient condition is imposed. Conditions such as discharge, channel slope, channel width and vegetation density used in the computation are given same as the present experimental conditions.

\section{Results and Discussion}

\subsection{Validation}

Validation of the model is conducted through comparisons with experimental data available in the literature reported by Tsujimoto and Kitamura [33]. They carried out laboratory experiments to investigate the hydraulic characteristics between a vegetated open channel flow and an open channel flow, and the depth-averaged velocity and the Reynolds stress were measured. The flume used in the experiments was $12 \mathrm{~m}$ long and $0.4 \mathrm{~m}$ wide where the vegetation zone was $0.12 \mathrm{~m}$ wide located at the side wall, consisting bomboos with diameter of $0.0015 \mathrm{~m}$. The flow conditions were water depths of $0.0457 \mathrm{~m}$ for run 1 and $0.0428 \mathrm{~m}$ for run 2 with a slope of 0.0017 . In the experimental runs 1 and 2, the spacing of bamboos was $0.028 \mathrm{~m}$ and $0.02 \mathrm{~m}$, respectively. The computational grid used in the present study was 240 and 40 in the $x$ - and $y$-directions, respectively. Two turbulence models are tested with the 0 -equation model and the $k-\varepsilon$ model. Figure $3 \mathrm{a}, \mathrm{b}$ show comparisons of experimental data and computed profiles of the depth-averaged velocity distribution. 

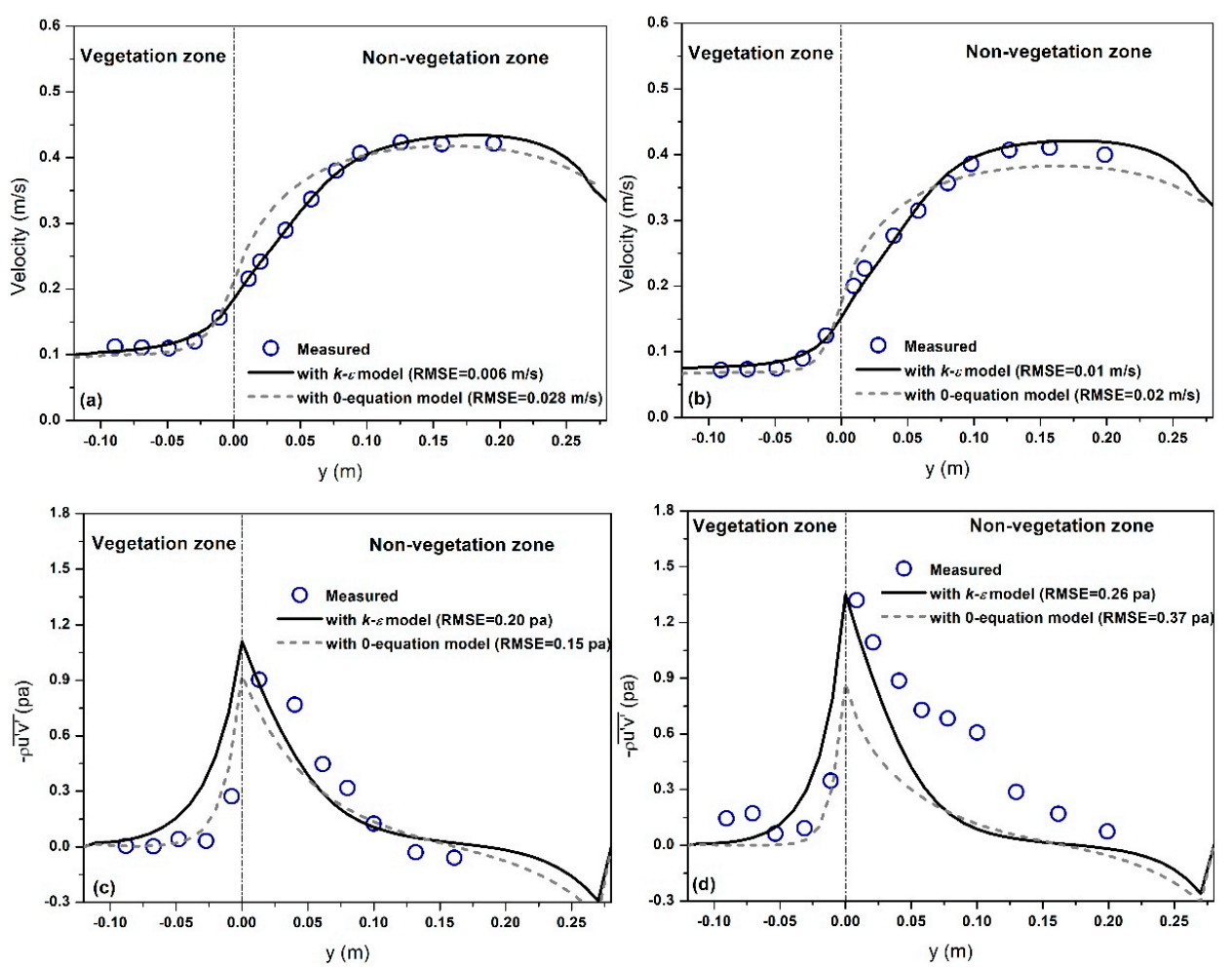

Figure 3. Comparison of experimental and computed profiles: (a) depth-averaged velocity for run-1; (b) depth-averaged velocity for run-2; (c) Reynolds stress for run-1; (d) Reynolds stress for run-2.

It can be seen that the velocity profiles in the vegetation zone are nearly uniform in the lateral direction, and the velocity rapidly increases from the interface between the vegetation zone and the open channel, $y=0$, and then it decreases near the side wall. The velocity distributions with the $k-\varepsilon$ model agree well with the experimental data, but the velocity profiles with 0 -equation model show discrepancies close to the interface between them. In particular, the high velocity gradient occurs because a strong shear layer is formed between the vegetated zone and the open channel, and the mass and momentum exchange take place between them. The generation of turbulence and the eddy viscosity seems to be not reproduced accurately using the 0 -equation model, so that the depth-averaged velocity profiles with the 0 -equation model are over-estimated close to the interface in the open channel. Figure $3 c$ and $d$ present comparisons of experimental data and computed profiles of the Reynolds stress distribution. The maximum values of the Reynolds stress are found at the interface in both results. Overall, computed profiles with the $k-\varepsilon$ model are in better agreement than computed ones with the 0-equation model, compared to experimental data, even though the profiles of the Reynolds stress are underestimated in the open channel. The Reynolds stress is proportional to the velocity gradient in the lateral direction, so that the high Reynolds stress indicates the mass and momentum exchange become high. To further verify the reliability of the numerical simulation, the root mean square error (RMSE) is used to evaluate the accuracy of the numerical results. The RMSE should be small to ensure a good agreement between the experimental and simulated results. As can be seen in Figure 3, the values of RMSE for the $k-\varepsilon$ model are smaller than those of the 0-equation model, so that it is found, as a whole, that the distributions of the depth-averaged velocity and the Reynolds stresses are predicted well by the present computational model using the $k-\varepsilon$ model. Therefore, the $k-\varepsilon$ turbulence model is only employed for the next computations the in present study.

\subsection{Sensitivity to Angle of Repose}

In the computations, a bank erosion process is affected by the angle of repose. In simplified bank erosion model used in this study, the bank erosion is calculated that as local bed slope, which is 
calculated using the bed elevation of neighboring grids is steeper than designated angle of repose, bank is collapsed regardless of whether bank is submerged or not. In order to check the sensitivity to angle of repose for the bank erosion model, three different values of the angle of repose $(\phi=25,30$ and 35 degrees) are tested, which is chosen from pervious literatures [5,34]. Figure 4 shows a comparison of cross-sectional bed elevation at the mid-channel of case 2 .

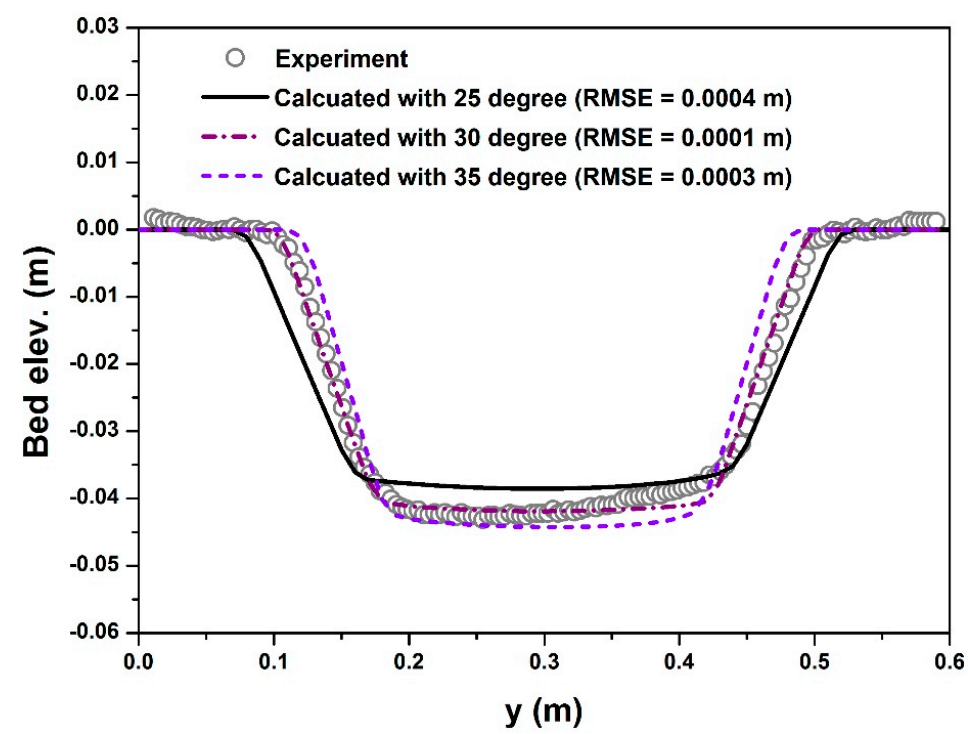

Figure 4. Comparison of cross-sectional bed elevation without the patch.

Overall, the value of RMSE is the smallest for the value of 30 degrees of angle of repose and the agreement between experimental and computational data appears to be good, and particularly, the bank slopes are satisfactory. It is observed that the rate of bank erosion decreases with the greater angle of repose in Figure 4, so that as the angle of repose becomes smaller, the bed elevation increases due to fact that the amount of eroded sediment increases, and then it is deposited on the low-water channel. On the other hand, the bank slope becomes steeper as the angle of repose is larger. Processes of bank erosion as well as the bed elevation in the low-water channel are significantly affected by the angle of repose. It is found that as a whole, angle of repose of 30 degrees, which is chosen by trial and error, is in agreement through a comparison with experimental data, and then, the value of 30 degrees is set in the present study.

\subsection{Variation of Bed Elevation}

Vegetation introduced in open channels affects significantly water depth, velocity, flow directions and channel morphology as compared with non-vegetated channels. Figure 5 shows comparisons of variation of bed elevation with varying patch densities between experimental and computational results for case 3 .

Without the patch of vegetation, the channel is expanded with lateral bank erosion in Figure 5a. When the vegetation patch is introduced in the channel, channel widening with bank erosion occurs considerably downstream and opposite of the patch, and then it leads to the change of flow directions toward the opposite region and further downstream of the patch. Such flows make it possible to erode banks, again (Figure 5b,c). Sedimentation is observed in the mid-channel and downstream of the patch. Also, sediment particles are deposited within and near the patch due to reduced bed shear stress caused by additional drag. In all cases, the flow conditions are above the threshold of particle motion, so that the sediment eroded from banks upstream of the patch is transported downstream, and then it is deposited at the region of relatively low shear stress, i.e., it is near or within the patch. It is found that sediment deposited within the patch decreases as the patch density becomes higher. As flow approaches the patch, flow is diverted away from the patch because of drag. Sediment passing 
through the patch is also reduced as the patch density becomes higher since higher diversion of flow carries away greater sand particles from the patch. In other words, the amount of deposition in and behind the patch decreases with increasing patch density. The added patch in an open channel leads to significant bank erosion directly opposite and further downstream of the patch, and deposition downstream of the patch. Then, channels seem to meander downstream of the patch in Figure 5. In fact, the present experiments are conducted for $2 \mathrm{~h}$ before flow reaches the side walls. However, if the duration becomes longer and the channel width is enough wide, we expect that the amplitude of meandering channel may be increased and the channel shape would be more pronounced. Thus, a vegetation patch in open channels is able to influence channel geometries significantly. Bennett et al. [7] investigated fluvial response to alternating patch of vegetation, which consisted of wooden dowels and located along the wall. The alternating patch was able to create meandering channel and the amplitude of the thalweg could be adjusted by patch density. We conducted several experiments with a patch, the results showed similar trends, which implies that a single patch in straight open channels with erodible bank is able to create meandering geometries downstream of the patch. Case 3 was presented herein for illustration, but processes of erosion and deposition were almost similar to other cases.

Numerical model reproduced reasonably spatial patterns of erosion and deposition near the emergent patch. Numerical results show that channel widening with bank erosion opposite and downstream of the patch as well as deposition downstream from the patch is predicted quite well for all patch densities. In the directly opposite patch, however, slightly more bank erosion is observed and less deposition is found in numerical results. The depositional pattern within the patch is also somewhat different from experimental ones.
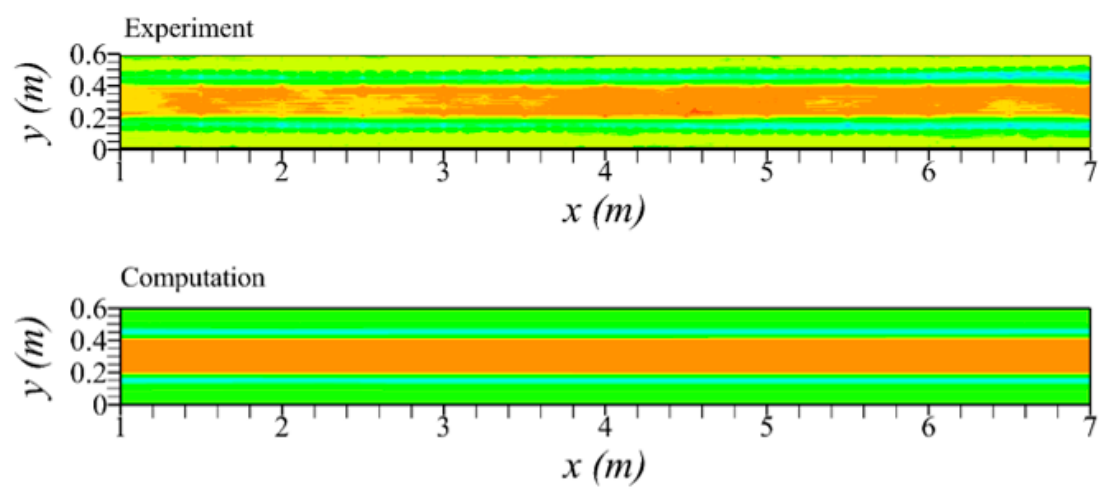

(a) Non-vegetated Channel
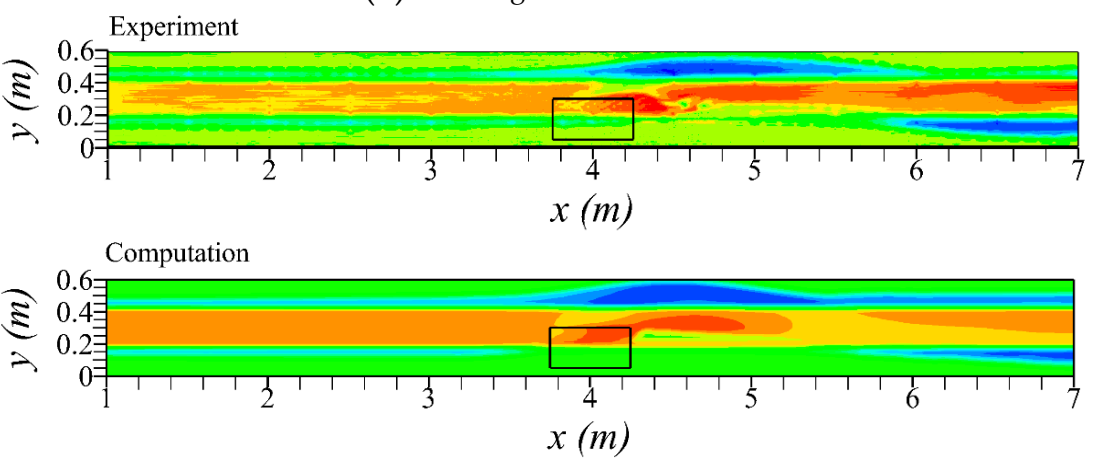

(b) Low density (LD)

Figure 5. Cont. 

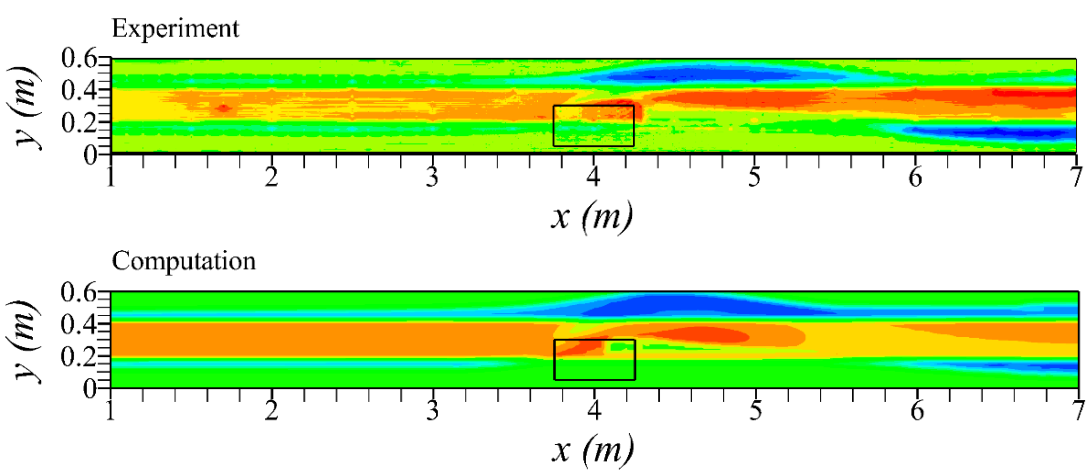

(c) High density (HD)

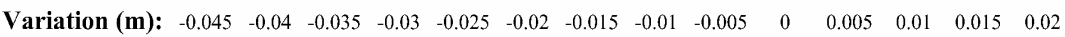

Figure 5. Comparison of variation of bed elevation between experiment and computation for case 3:

(a) non-vegetated channel; (b) low density; (c) high density. Flow is from left to right. The solid line is a patch of vegetation.

Those discrepancies between experimental and numerical results are due probably to three-dimensional effects caused by flow around individual cylinders within the patch. Inside the patch, in particular, the turbulence levels are elevated around individual cylinders, and those are responsible for moving sediment particles further downstream. This indicates high bottom shear stresses occur in the vicinity of cylinders due to wake turbulences, whereas the model in the present study predicts a reduction of bottom shear stresses within the patch, deposited throughout the patch. To simulate such morphological changes, a three-dimensional model should be used with the wall function considering every cylinder. Overall, the model is able to predict well general spatial patterns of erosion and deposition near the patch and the temporal progressing of the channel adjustments, although the small-scale erosion around individual cylinders cannot be simulated.

Figure 6 displays spatial patterns of erosion and deposition around the patch for case 2 . These are taken end of each experiment, draining water and removing the patch. It is observed in LD and HD that sediment is deposited within and behind the patch, whereas small-scale scour occurred in the immediate vicinity of cylinders (Figure 6).
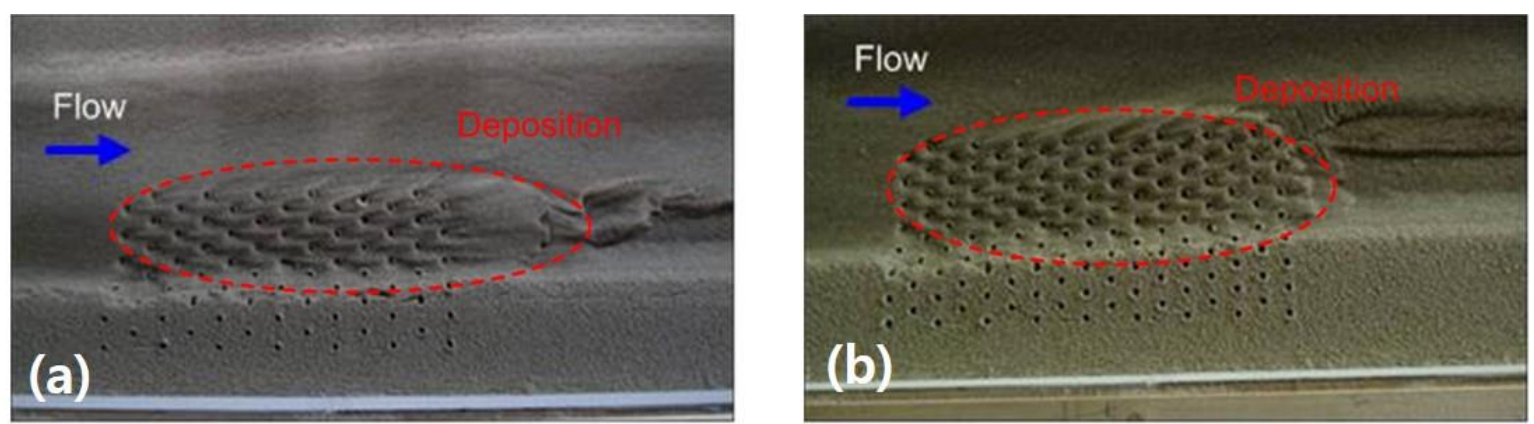

Figure 6. Spatial pattern of erosion and deposition within and around the patch for (a) low density and (b) high density.

Figure 7 depicts comparisons of cross-sectional bed elevation between experimental and numerical results at $3.0 \mathrm{~m}, 3.8 \mathrm{~m}, 4.0 \mathrm{~m}$ and $4.75 \mathrm{~m}$ for case 2. It indicates that the sections of $3.0 \mathrm{~m}$ and $4.75 \mathrm{~m}$ are located upstream and downstream of the patch, respectively, and others are near the patch. 

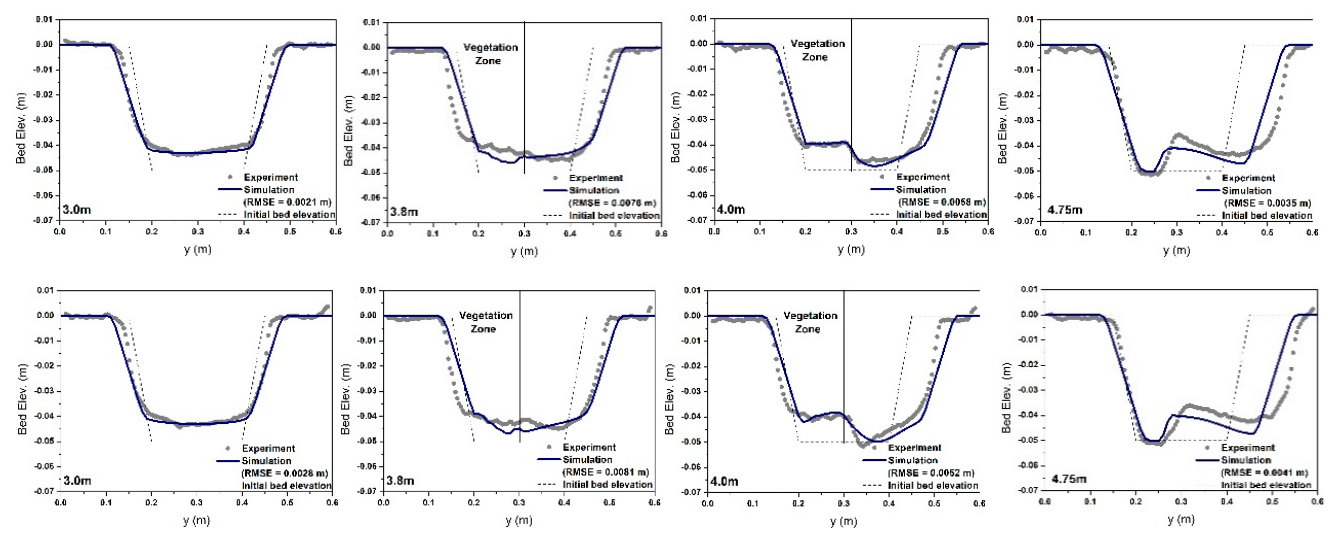

Figure 7. Comparison of bed elevation between experiment and computation for low density (upper) and high density (lower) of case 2.

It can be seen that the channel widening with lateral bank erosion occurs and sediment is deposited in low-water channels at $3.0 \mathrm{~m}$ in Figure 7 . The bed elevations increase about $0.6 \mathrm{~mm}$ and present symmetric cross-sections in both experimental and numerical ones. At $3.8 \mathrm{~m}$, sediment accumulation is observed both within the patch and in the non-vegetated channel, and the lateral bank erosion takes place directly opposite the patches. Simulated results agree with experimental ones. At $4.0 \mathrm{~m}$, considerable lateral bank erosion is observed opposite the patch due to increased velocity. Local scour is observed around the patch, and its depth increases with increasing patch densities in experimental results, which is consistent with previous studies [10]. This is attributed to diversion of flow and the secondary current caused by the added patch in open channels. Additional vegetation drag in the streams increases the total resistance, and then flow is diverted away from the patch. The diversion of flow is able to lead to erosion opposite and near the patch because of accelerated velocity and elevated turbulence, and their magnitude increases with increasing patch density. It is observed at $4.75 \mathrm{~m}$ that behind the vegetation patch, the bed elevation is nearly constant, decreasing bed shear stress, whereas the lateral bank erosion and deposition occur opposite the patch for all patch densities. Also, the bank slopes behind and within the patches have almost identical to initial bank slopes regardless of the patch density, reducing bed shear stress, i.e., decelerating flow velocity through the patch induced by drag. Bank vegetation increases the strength of banks and it is stabilized by vegetation root $[35,36]$. Then, they observed that high vegetation on banks caused lower channel widening with bank erosion than poor vegetation on banks. The simulated results are in good qualitative agreement with experimental ones. Overall, the numerical model predicted reasonably spatial patterns of erosion and deposition near the vegetation patch.

It is observed in experimental results that localized scour takes place near lateral edge of the patch (Figure 7). Figure 8 shows maximum scour depth observed near the opposite patch is presented with four experimental cases as a function of the patch density.

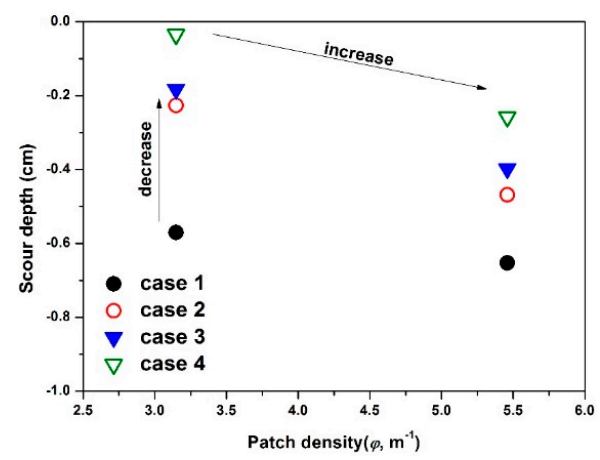

Figure 8. Maximum scour depth around the vegetation patch according to the patch density. 
It can be seen that scour depth increases with increasing the patch density in all cases. In the experimental data, main mechanism of scour near the vegetation patch is due to diversion of flow, as discussed above, and its magnitude increases as the patch density becomes higher since flow rate diverted away from the patch increases in the non-vegetated channel. The increase in patch density reflects the increase in resistance due to drag and then, it leads to more acceleration in the non-vegetated channel. It is found that as the flow rate or the channel slope decreases, scour depth becomes deeper. This is attributed to a decrease in sediment loading supplied from upstream of the patch. Sediment caused by the lateral bank erosion from upstream of the patch is transported downstream. The increases in flow rate or channel slope induces an increase in bed shear stress, and it leads to higher magnitude of bank erosion. Thus, greater sediment is delivered from upstream of the patch to downstream and it is deposited close to the patch.

Figure 9 shows longitudinal bed profiles of variation of bed elevation $(x=3 \mathrm{~m}-5 \mathrm{~m})$ at $y=0.22 \mathrm{~m}$ for case 2 to investigate detailed behaviors of erosion and deposition through the patch. For the low density (LD) patch in Figure 9a, sediment begins to accumulate from upstream of the patch and the deposition continues some distance within the patch. Sediment is deposited within the patch due to reduced bed shear stress, whereas some sediment particles in the immediate vicinity of individual cylinders are transported further downstream because of elevated turbulence kinetic energy. The flow passing through vegetated region induces stem wakes and those could contribute additional turbulent kinetic energy [37] which is responsible for particle entrainment. Deposition is observed until roughly $x=4.5 \mathrm{~m}$ beyond the patch in experimental data and the bed profile of the simulation in the LD patch matches the experimental one quite well. For the high density (HD) patch, depositional patterns show a similar trend, compared to the LD patch but localized scour is observed at the leading edge of the patch. Sediment scoured at the leading edge of the patch is transported further downstream of the region or is diverted away to the open channel. The simulated results show slightly different morphological changes where in turn, simulated depositional distance is shorter than that of experimental data, whereas simulated deposition heights near the leading edge of the patch become slightly higher.
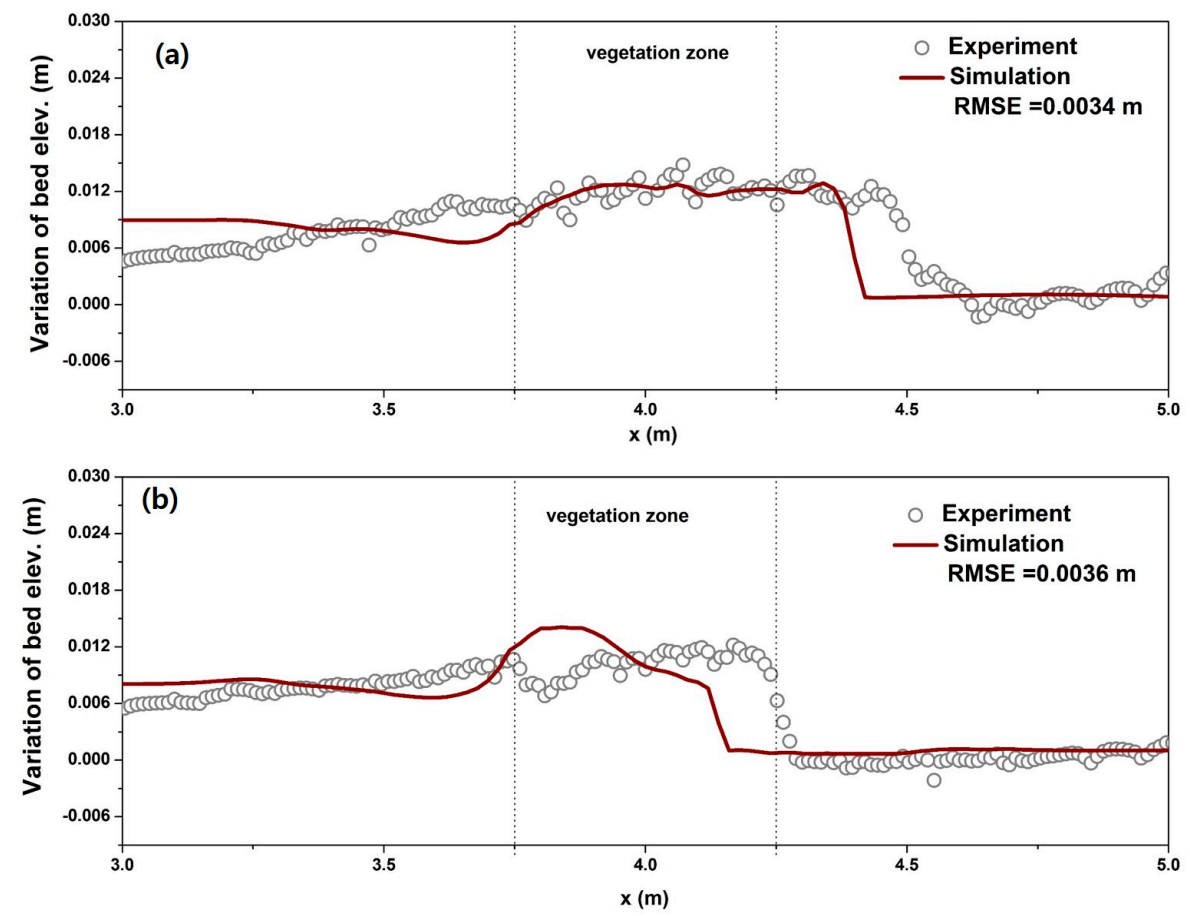

Figure 9. Longitudinal profiles of variation of bed elevation at $\mathrm{y}=0.22 \mathrm{~m}$ for case 2: (a) low density and (b) high density. 
Bouma et al. [10] found similar trends in field observations and those were simulated by a three-dimensional code. They demonstrated that the model was not able to correctly reproduce leading edge effects since complex flow caused by individual stems were not considered. As the cylinder spacing is reduced, flow begins to be interfered by upstream and lateral cylinders. The fact that interference of flow caused by cylinders increases turbulence levels supports the local scour at the leading edge of the patch. Also, reduced spacing between cylinders leads to the increased size of horseshoe vortex and reinforcement of downstream cylinders [38,39], so that those induce high bed shear stress and consequently high erosion. However, the amount of sediment deposition within the patch between experimental and numerical ones seems to be similar, even though the distances of deposition are slightly under-estimated in the patch. Zong and Nepf [12] described the deceleration in the longitudinal velocity began upstream of the patch and it continued to decrease until diversion of flow was ended. Then, the fact that the distance of divergence flow decreases with increasing patch density supports decreased depositional distance with increasing patch density in both experimental and simulated results.

The amount of deposited sediment increases as the patch density decreases due to the reduction of diversion of flow or the channel slope and the flow rate become greater. The simulated amount of sediment accumulated within and near the patch agrees well with experimental data, which confirms that since the numerical model does not take into account elevated turbulence adjacent to cylinders within the patch, the depositional distance through the patch is under-predicted. Through comparison (Figure 10), this indicates that the present numerical model not only offers reasonable perditions of morphological changes and the amount of deposited sediment within and near the patch, but also reproduces important features of erosion and deposition, yet needs to be refined to deal accurately with the effect of leading edge of the patch.

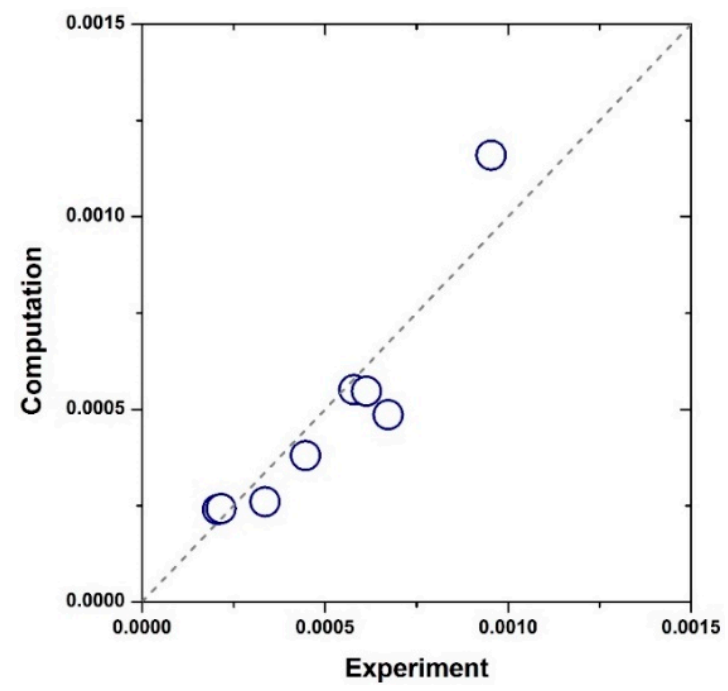

Figure 10. Comparison between experiment and computation of sediment deposition within and around the patch.

Figure 11 depicts lateral unit discharges and bed profiles with different times at $x=4.3 \mathrm{~m}$ for case 2 of the HD patch. Distribution of unit discharge is varied with time in both behind the patch and opposite the patch. It is found that maximum unit discharge occurs at the central channel opposite the patch in the beginning (i.e., after $30 \mathrm{~min}$ ), whereas unit discharge is considerably reduced behind the patch. Unit discharge decreases with time in both opposite and behind the patch, as lateral bank erosion opposite the patch increases. This reveals that $77 \%$ and $83 \%$ of the total discharge are conveyed opposite the patch after $30 \mathrm{~min}$ and $120 \mathrm{~min}$, respectively, so that discharge passing through the patch decreases with the lateral channel widening opposite the patch. 

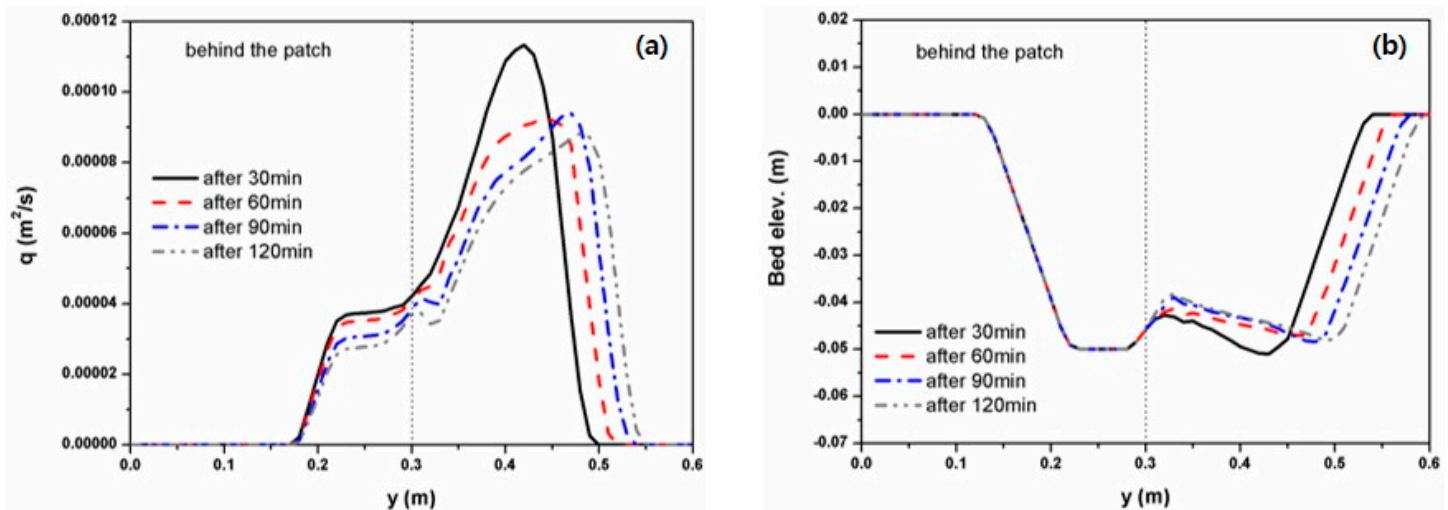

Figure 11. Computational results of (a) lateral unit discharge and (b) bed profile with different time at $\mathrm{y}=4.3 \mathrm{~m}$ for the high density of case 2 .

Figure 12 shows lateral unit discharges and bed profiles with different patch densities at $x=4.3 \mathrm{~m}$ for case 2. It can be seen that shapes of unit discharge and cross-section bed profile without the patch are symmetric, and it differs from that with the patch. Maximum unit discharge with the patch is greater than that without the patch. Maximum unit discharge opposite the patch is quite similar regardless of the patch density and moves increasingly toward the opposite bank of the patch as the channel widening increases with increasing patch density. Also, unit discharge passing through the opposite patches increases with increasing patch density from $79 \%$ to $88 \%$, transferring greater discharge from the patch to the non-vegetated channel. On the other hand, behind the patch, unit discharge decreases with increasing patch density, where in turn, flow velocity is significantly reduced, so that the bank erosion is reduced compared to that without the patch. The vegetation patch could create diverse flows in stream habitats and increase bank strength and stability within and behind itself. In particular, a refuge area is formed behind the patch due to low velocities and turbulences, so that fishes are sheltered in the area, with the reasoning that slower flow requires less energy for them. Then, the vegetation patch may provide a wide range of aquatic habitats and create a better ecosystem.
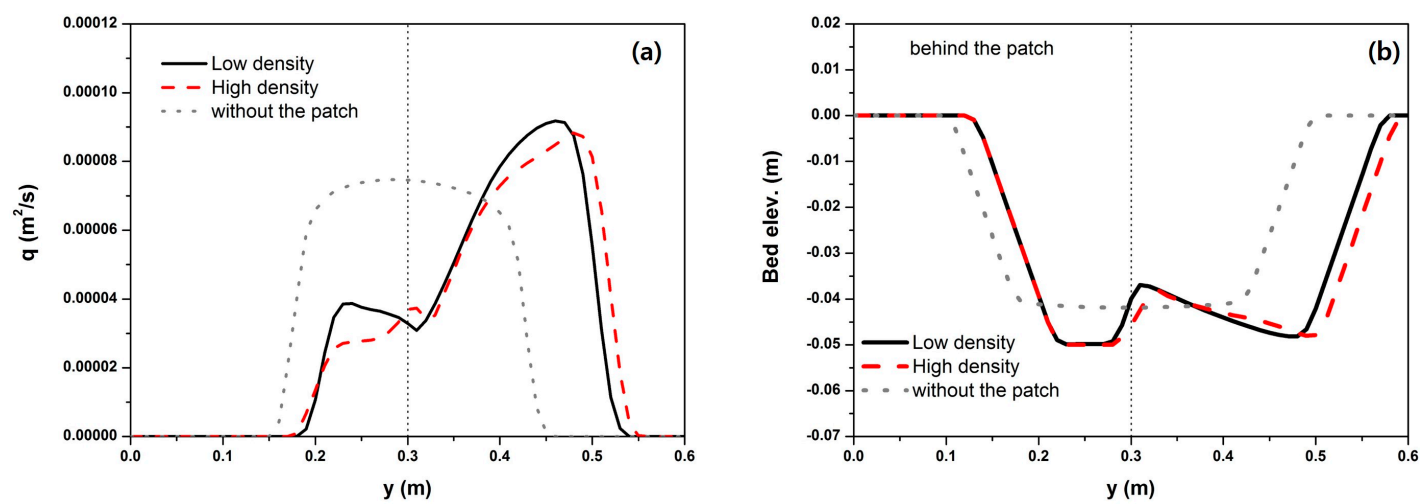

Figure 12. Computational results of (a) lateral unit discharge and (b) bed profile with different patch densities at $\mathrm{y}=4.3 \mathrm{~m}$ for case 2 .

\section{Conclusions}

In this study, we described morphological changes with a vegetation patch by means of laboratory experiments and numerical simulations. Four cases were tested with two patches and without the patch to elucidate the influence of the patch in an open channel with erodible bank. A two dimensional depth averaged model was proposed to simulate flow and sediment transport in open channels with vegetation, and the model was applied to partly vegetated open channel flows with a movable bed experimentally conducted in this study. 
For the non-vegetated channel, channel widening with bank erosion occurred, whereas when the patch was added in an open channel, the bank directly opposite the patch was eroded considerably, and sediment was deposited within and downstream of the patch. The numerical model simulated spatial patterns of erosion and deposition with the vegetation patch well. Significant scour was observed near the lateral edge of the patch due to diversion of flow. Its depth increased with increase in the patch density, and decreased with increasing flow discharge and channel slope. Distinct morphological changes were observed within the patch. Small-scale scour took place in the immediate vicinity of cylinders. The simulated results matched experimental data for the LD and HD patches quite well, even though the numerical model could not predict local scour at the leading edge of the patch because of the effect of three-dimensional flow and interference. The depositional distance decreased with an increase in the patch density in both experimental and numerical results. The depositional distance and the amount of sediment through the patch decreased with an increase in the patch density. Channel-widening with bank erosion increased with the patch density and hydraulic condition (i.e., flow discharge and channel slope). The numerical model predicted the process of channel adjustment over time well. Unit discharge passing through non-vegetated channel not only increased with time due to channel widening with lateral bank erosion but also increased with increasing patch density.

The present model could capture the important features of morphological response to a vegetation patch in open-channel flows with erodible bank, and so could be employed as a useful tool for designing and assessing river restorations.

Author Contributions: H.S.K., I.K. and Y.S. conceived and designed experiments and numerical simulations; H.S.K. performed the experiment and simulation, and analyzed the data; I.K. conducted an analysis of results; Y.S. provided motivation and contributed interpretation of results; H.S.K. wrote the paper; and all authors participated in final review and editing of the paper.

Funding: This research was funded by the internal project of Korea Institute of Civil Engineering and Building Technology [KICT internal Research Fund: 20190120].

Conflicts of Interest: The authors declare no conflict of interest.

\section{References}

1. Leu, J.M.; Chan, H.C.; Jia, Y.; He, Z.; Wang, S.S.Y. Cutting management of riparian vegetation by using hydrodynamic model simulations. Adv. Water Resour. 2005, 31, 1299-1308. [CrossRef]

2. Shimizu, Y.; Tsujimoto, T. Numerical analysis of turbulent open-channel flow over vegetation layer using a k-eps turbulence model. J. Hydrosci. Hydraul. Eng. 1994, 11, 57-67.

3. Tsujimoto, T. Fluvial processes in streams with vegetation. J. Hydraul. Res. 1999, 37, 789-803. [CrossRef]

4. Coulthard, T. Effects of vegetation on braided stream pattern and dynamics. Water Resour. Res. 2005, 41, W04003. [CrossRef]

5. Jang, C.-L.; Shimizu, Y. Vegetation effects on the morphological behavior of alluvial channels. J. Hydraul. Res. 2007, 45, 763-772. [CrossRef]

6. Tal, M.; Paola, C. Dynamic single-thread channels maintained by the interactions flow and vegetation. Geology 2007, 35, 347-350. [CrossRef]

7. Bennett, S.; Wu, W.; Alonso, C.; Wang, S.S.Y. Modeling fluvial response to in-stream woody vegetation: Implications for stream corridor restoration. Earth Surf. Process. Landf. 2008, 33, 890-909. [CrossRef]

8. White, B.; Nepf, H.M. A vortex-based model of velocity and shear stress in a partially vegetated shallow channel. Water Resour. Res. 2007, 44, W01412. [CrossRef]

9. Choi, S.-U.; Kang, H. Numerical investigations of mean flow and turbulence structures of partly-vegetated open-channel flows using the Reynolds stress model. J. Hydraul. Res. 2006, 44, 203-217. [CrossRef]

10. Bouma, T.J.; van Duren, L.A.; Temmerman, S.; Claverie, T.; Blanco-Garcia, A.; Ysebaert, T.; Herman, P.M.J. Spatial flow and sedimentation patterns within patches of epibenthic structures: Combining field, flume and modeling experiments. Cont. Shelf Res. 2007, 27, 1020-1045. [CrossRef]

11. Rominger, J.; Lightbody, A.; Nepf, H. The Effects of Added Vegetation on Sand Bar Stability and Stream Hydrodynamics. J. Hydraul. Eng. 2010, 136, 994-1002. [CrossRef] 
12. Zong, L.; Nepf, H. Spatial distribution of deposition within a patch of vegetation. Water Resour. Res. 2011, 47, W03516. [CrossRef]

13. Darby, S.E. Effect of riparian vegetation on flow resistance and flood potential. J. Hydraul. Eng. 1999, 125, 443-454. [CrossRef]

14. Tominaga, A.; Nagao, M.; Nezu, I. Flow structure and momentum transport processes in curved open channels with vegetation. In Proceedings of the 28th Congress of International Association of hydraulic Research, Graz, Austria, 22-27 August 1999.

15. Wu, W.; Shields, F.D., Jr.; Bennett, S.; Wang, S.S.Y. A depth-averaged two-dimensional model for flow, sediment transport, and bed topography in curved channels with riparian vegetation. Water Resour. Res. 2005, 41, W03015. [CrossRef]

16. Li, S.S.; Millar, R.G. A two-dimensional morphodynamic model of gravel-bed river with floodplain vegetation. Earth Surf. Process. Landf. 2010, 36, 190-202. [CrossRef]

17. Barfield, B.J.; Tollner, E.W.; Hayes, J.C. Filtration of sediment by simulated vegetation: I. Steady-state flow with homogeneous sediment. Trans. Am. Soc. Civ. Eng. Soil Water Div. 1979, 4451, 540-556. [CrossRef]

18. Tanino, Y.; Nepf, H.M. Laboratory investigation of mean drag in a random array of rigid, emergent cylinders. J. Hydraul. Eng. 2008, 134, 34-41. [CrossRef]

19. Stone, B.M.; Shen, H.T. Hydraulic resistance of flow in channels with cylindrical roughness. J. Hydraul. Eng. 2002, 128, 500-506. [CrossRef]

20. Kimura, I.; Hosoda, T. Computations of 2D shallow mixing layers in open channel flows using a modified depth-averaged model. In Proceedings of the 4th International Symposium on Environmental Hydraulics and 14th Congress of Asia and pacific Division, Hong Kong, China, 15-18 December 2004; pp. 981-987.

21. Nezu, I.; Nakagawa, H. Turbulence in Open Channel Flows; IAHR Monograph: Rotterdam, The Netherlands, 1993.

22. Launder, B.E.; Spalding, D.B. The numerical computation of turbulent flow. Comput. Methods Appl. Mech. Eng. 1974, 3, 269-289. [CrossRef]

23. Lopez, F.; Garcia, M. Open Channel Flow through Simulated Vegetation: Turbulence Modeling and Sediment Transport; Wetlands Program Technical Report WRP-CP-10; Waterways Experiment Station: Vicksburg, MS, USA, 1997.

24. Rodi, W. Turbulence Model and Their Application in Hydraulics; IAHR Monograph: Delft, The Netherlands, 1993.

25. Tsujimoto, T. Development sand island with vegetation in fluvial fan river under degradation. Water Resour. Eng. 1998, 1, 574-579.

26. Kovacs, A.; Parker, G. A new vectorial bedload formulation and its application to the time evolution of straight river channels. J. Fluid Mech. 1994, 267, 153-183. [CrossRef]

27. Ashida, K.; Michiue, M. Study on hydraulic resistance and bed-load transport rate in alluvial streams. Proc. JSCE 1972, 201, 59-69. [CrossRef]

28. Yamaguchi, S.; Izumi, N. Weakly nonlinear analysis of dunes by the use of a sediment transport formula incorporating the pressure gradient. In Proceedings of the 4th IAHR symposium on River, Coastal and Estuarine Morphodynamics (RCEM), Urbana, IL, USA, 4-7 October 2005.

29. Hasegawa, K. Hydraulic Characteristics of Mountain Streams and Their Practical Application, Lecture Notes of the 33rd Summer Seminar on Hydraul; JSCE A-9-1-20; Japan Society of Civil Engineers: Tokyo, Japan, 2000. (In Japanese)

30. Engelund, F. Flow bed topography in channel bend. J. Hydraul. Div. Am. Soc. Civ. Eng. 1974, 100, 1631-1648.

31. Kikkawa, H.; Kitagawa, A.; Ikeda, S. Flow and bed topography in curved open channels. J. Hydraul. Div. 1976, 102, 1327-1342.

32. Hasegawa, K. Hydraulic Research on Planimetic Forms, Bed Topographies and Flow in Alluvial Rivers. Ph.D. Thesis, Hokkaido University, Hokkaido, Japan, 1984. (In Japanese).

33. Tsujimoto, T.; Kitamura, T. Lateral bed load transport and sand-ridge formation near vegetation zone in an open channel. J. Hydrosci. Hydraul. Eng. 1995, 13, 35-45.

34. Jang, C.-L.; Shimizu, Y. Numerical simulations of behavior of alternate bars with different bank strengths. J. Hydraul. Eng. 2005, 43, 595-611. [CrossRef]

35. Hicken, E.J. Vegetation and river channel dynamics. Can. Geographer. 1984, 28, 111-126. [CrossRef]

36. Millar, R.G.; Qucik, M.C. Effect of bank stability on geometry of gravel rivers. J. Hydraul. Eng. 1993, 119, 1343-1363. [CrossRef] 
37. Nepf, H.M.; Vivoni, E.R. Flow structure in depth-limited vegetated flow. J. Geophys. Res. 1999, 105, 547-557. [CrossRef]

38. Raudkivi, A.J. Loose Boundary Hydraulics, 3rd ed.; Pergamon Press: Oxford, UK, 1990.

39. Ataie-Ashtiani, B.; Beheshti, A.A. Experimental investigation of clear-water local scour at pile groups. J. Hydraul. Eng. 2006, 132, 1100-1104. [CrossRef] 